\title{
Diminuição dos níveis de cálcio e fósforo em dietas com farelo de arroz integral e enzimas sobre o desempenho de frangos de corte
}

\author{
Decrease of the levels of calcium and phosphorus in diets with whole rice meal and enzymes on the \\ performance of broilers
}

\author{
Ricardo dos Santos ${ }^{1}$ Irineo Zanella $^{2}$ Elivelton Luiz Bonato ${ }^{3}$ Alexandre Pires Rosa ${ }^{4}$ \\ Leandro Magon ${ }^{3}$ Sandra Paula Gasparini ${ }^{5}$ Lourdes Bernadete Padilha Brittes $^{6}$
}

RESUMO

$O$ objetivo deste trabalho foi estudar o efeito do níveis crescentes de Farelo de Arroz Integral (FAI) sobre o desempenho de frangos de corte e avaliar a redução dos níveis de cálcio $(\mathrm{Ca})$ e do fósforo $(\mathrm{P})$, quando as dietas foram suplementadas com enzimas exógenas. Foram utilizados 480 pintos (fêmeas) Cobb com 12 dias de idade, distribuídas em 8 tratamentos avaliando 4 níveis de FAI $(0 \%, 10 \%, 20 \% e$ $30 \%$ ) com e sem enzima, com 3 repetições de 20 aves por tratamento. Nas dietas que continham enzimas, foram diminuídos os níveis de Ca e P em 0,1\%, em todas as fases criatórias. Com a adição de níveis crescentes de farelo de arroz integral nas dietas, houve uma regressão linear significativa $(P<0,05)$ com redução no peso corporal, consumo de ração e no ganho de peso das aves. A conversão alimentar aumentou linearmente à medida que se aumentavam os níveis de FAI, mas não houve efeito significativo $(P>0,05)$. A suplementação enzimática nos diferentes níveis de FAI, não apresentou diferença estatística significativa. A utilização de baixos níveis de Ca e P não prejudicou o desempenho das aves.

Palavras-chave: enzimas, farelo de arroz integral, desempenho, cálcio e fósforo.

\section{ABSTRACT}

The objective of this work was to study the effect of the growing levels of whole rice meal (WRM) on the performance of broilers chickens and to evaluate the reduction of the calcium ( $\mathrm{Ca}$ ) and phosphorus $(\mathrm{P})$, when the diets were supplemented with enzymes exogenous. A total of 480 chicks (females) Cobb 12 days old were used, distributed in 8 treatments evaluating 4 levels of WRM (0\%, 10\%, 20\% and $30 \%)$, with and without supplementation of a multienzyme complex, with 3 repetitions of 20 poultries for treatment. In the diets that contained enzymes, the levels of $\mathrm{Ca}$ and $\mathrm{P}$ were decreased in $0,1 \%$, in all the development phases. With the addition of growing levels of Whole rice meal in the diets, there was a significant lineal regression $(P<0.05)$ with redution of the body weight, feed intake and of the weight gain of the broilers. The feed conversion increased lineally as they increased the levels of WRM, but there was no significant effect $(P>0.05)$. The enzymatic supplementation in the different levels of WRM didn't present significant statistical difference. The use of low levels of $C a$ and $P$ didn't harm the acting of the birds.

Key words: enzymes, integral rice bran, performance, calcium and phosphorus.

\section{INTRODUÇÃO}

O Farelo de Arroz Integral (FAI) é uma matéria prima disponível no mercado brasileiro e pode ser utilizado nas dietas visando diminuir os custos de produção, substituindo o milho que é a matéria prima que mais dispende custos às rações avícolas. No entanto, a utilização do FAI nas dietas de frangos de corte está limitada em função da presença de polissacarídeos não amiláceos (PNA), que acabam formando um gel no trato intestinal, afetando negativamente a absorção de nutrientes. Os PNA não podem ser metabolizados pelas enzimas endógenas das aves, uma vez que estas não produzem alfagalactosidase no trato gastro-intestinal, segundo

\footnotetext{
${ }^{1}$ Acadêmico do Curso de Medicina Veterinária, Universidade Federal de Santa Maria (UFSM), bolsista do PIBIC-CNPQ

${ }^{2}$ Professor Adjunto, Departamento de Zootecnia, UFSM, 97105-900, Santa Maria, RS. E-mail: izanella@ccr.ufsm.br - Autor para correspondência.

${ }^{3}$ Acadêmicos do Curso de Medicina Veterinária, UFSM.

${ }^{4}$ Professor Adjunto, Departamento de Zootecnia, UFSM.

${ }^{5}$ Acadêmico do Curso de Zootecnia, UFSM.

${ }^{6}$ Zootecnista, Departamento de Zootecnia, UFSM.
} 
KELSAI(1978), Gitzelman and Auricchia (1965) citados por KORIN et al. (1991), FIALHO (1991), TEIXEIRA (1994), DOMENE(1996) e PENZ (1998).

Entretanto, WHITE et al. (1983) já haviam demonstrado em frangos que os beta-glucanos e BEDFORD \& CLASSEN (1992) que arabinoxilanos são substâncias solúveis e viscosas, que se dissolvem da parede celular do endosperma, reduzem a digestibilidade da dieta, pois comprometem a absorção dos nutrientes e a difusão de todas as substâncias relacionadas com a digestão e a absorção.O emprego de complexos multienzimáticos, cada vez mais usuais no mercado, tem apresentado bons resultados na redução destes fatores antinutricionais, encontrados nos grãos de centeio, trigo e cevada, utilizado em rações de aves (VÖLKER \& TÜLLER, 1993; ROTTER et al.,1998).

A adição de enzimas permite o emprego de alguns ingredientes, muitas vezes, disponíveis e de utilização limitada devido a sua composição química ou a presença de inibidores nutricionais, os ingredientes ricos em fósforo fítico ou em polissacarídes não-amídicos, respectivamente (PENZ, 1998). Segundo RAVIDRAN et al. (1996), TORIN (1991) e ROSTAGNO (1998), o fósforo é um dos nutrientes mais caros da ração, e está a maior parte na forma de fósforo fítico ligado à molécula de fitato (fósforo fítico) podendo variar de 45 a $86 \%$ do fósforo total do alimento chegando próximo a $90 \%$ do total nos produtos de origem vegetal, respectivamente.

ZANELLA (2001) faz referência que, nos grãos de cereais, o fósforo encontra-se em média $66 \%$ ou mais na forma de fitato, e que os monogástricos não dispõem de fitase endógena para sua utilização. CONTE et al. (1999) explicam que esta condição se dá pela ausência ou existência irrelevante da enzima fitase endógena nos animais monogástricos, que teria a função de hidrolisar os grupos ortofosfato da molécula de fitato, tornando desta maneira o fósforo indisponível. O modo de ação da fitase é pela catálise do ácido fítico, liberando o fósforo. A ação desta enzima pode variar com a idade dos animais, especialmente em suínos, pelo $\mathrm{pH}$ do meio, pela temperatura da dieta, pelo tempo de conservação do produto e da dieta que contém a enzima (JONGBLOED et al., 1993). WENK (1993) comenta que a suplementação de enzimas exógenas pode aumentar a eficiência de ação das enzimas endógenas, reduzindo a quantidade de resíduos nutricionais que chegam ao intestino grosso, diminuindo a possibilidade de ação dos microorganismos naquela área do aparelho digestivo.

O objetivo deste experimento foi estudar o efeito dos níveis crescentes de FAI sobre o desempenho de frangos de corte e avaliar a redução do cálcio $(\mathrm{Ca})$ e do fósforo $(\mathrm{P})$, quando as dietas foram suplementadas com enzimas exógenas.

\section{MATERIAL E MÉTODOS}

O trabalho foi conduzido no Setor de Avicultura do Departamento de Zootecnia da Universidade Federal de Santa Maria, Santa Maria, RS no período compreendido entre 12 de julho a 23 de agosto de 2002.

Foram utilizados 480 pintos Cobb, fêmeas de 12 dias de idade, distribuídos em um delineamento experimental inteiramente casualizado em esquema fatorial 4x2, para avaliar 4 níveis de inclusão de FAI $(0 \%, 10 \%, 20 \%, 30 \%)$ com e sem suplementação enzimática, com 3 repetições de 20 aves por repetição. De 1 a 42 dias, as aves foram criadas em 24 boxes de $2,25 \mathrm{~m}^{2}$ cada, onde foram feitas as avaliações de desempenho. $\mathrm{Na}$ fase inicial, foram utilizados comedouros do tipo bandeja até os 7 dias de idade, sendo, depois, substituídos gradativamente pelo comedouro tubular. Também foram utilizados bebedouros do tipo pendular do primeiro, até o último dia. As aves receberam aquecimento por meio de campânulas com lâmpadas incandescentes de $150 \mathrm{~W}$ (capacidade para 50 pintos), durante os primeioros 16 dias de idade. De acordo com a temperatura ambiente e o comportamento das aves, as cortinas foram abertas gradativamente. As aves receberam água e ração ad libitum.

Foram utilizados 2 tipos de dietas fareladas, conforme a fase de criação: ração inicial ( 1 - 11 dias); crescimento ( 12 - 35 dias) e final (36 42 dias). Sendo que na fase inicial foi utilizada uma dieta basal para todos os tratamentos. As dietas foram isoproteicas e isocalóricas, conforme recomendações de ROSTAGNO (2000) demonstrado nas tabelas 1 e 2 . Nas dietas que continham enzimas, foram diminuídos os níveis de Ca de $0,95 \%$ para $0,85 \%$ e o nível de fósforo de $0,45 \%$ para $0,35 \%$, na fase inicial e crescimento (Tabela 1). Na fase final, os níveis $\mathrm{Ca}$ e $\mathrm{P}$ foram reduzidos de $0,88 \%$ para $0,78 \%$ e de $0,42 \%$ para $0,32 \%$, respectivamente (Tabela 2 ). O complexo multienzimático composto pelas enzimas protease, pentosanase e fitase foi adicionado nas dietas à razão de $1 \mathrm{~kg} /$ ton de acordo com as recomendações do fabricante.

Os parâmetros analisados foram peso corporal, consumo de ração, ganho de peso, conversão alimentar e índice bio-econômico. Para analisar a 
Tabela 1 - Composição Nutricional das dietas utilizadas durante a fase de crescimento (12-35 dias).

\begin{tabular}{|c|c|c|c|c|c|c|c|c|}
\hline Nutrientes & $0 \%$ (s/enz) & $0 \%$ (c/enz) & $10 \%$ (s/enz) & $10 \%$ (c/enz) & $20 \%$ (s/enz) & $20 \%$ (c/enz) & $30 \%$ (s/enz) & $30 \%$ (c/enz) \\
\hline PB (\%) & 21,35 & 21,39 & 21,73 & 21,75 & 21,70 & 21,70 & 21,70 & 21,70 \\
\hline EM (Kcal/Kg) & 3100 & 3100 & 3100 & 3100 & 3100 & 3100 & 3100 & 3100 \\
\hline Cálcio (\%) & 0,95 & 0,85 & 0,95 & 0,85 & 0,95 & 0,85 & 0,95 & 0,85 \\
\hline P.disp. (\%) & 0,45 & 0,35 & 0,45 & 0,35 & 0,45 & 0,35 & 0,45 & 0,35 \\
\hline Sódio (\%) & 0,18 & 0,18 & 0,18 & 0,18 & 0,18 & 0,18 & 0,18 & 0,18 \\
\hline Arginina (\%) & 1,36 & 1,36 & 1,32 & 1,32 & 1,25 & 1,25 & 1,19 & 1,19 \\
\hline Lisina (\%) & 1,08 & 1,08 & 1,11 & 1,11 & 1,12 & 1,11 & 1,12 & 1,12 \\
\hline Metionina (\%) & 0,35 & 0,35 & 0,35 & 0,35 & 0,35 & 0,35 & 0,35 & 0,35 \\
\hline Met + Cys (\%) & 0,70 & 0,71 & 0,71 & 0,71 & 0,70 & 0,70 & 0,70 & 0,70 \\
\hline Treonina (\%) & 0,73 & 0,73 & 0,73 & 0,73 & 0,73 & 0,73 & 0,73 & 0,73 \\
\hline Valina (\%) & 0,99 & 0,99 & 0,96 & 0,96 & 0,90 & 0,90 & 0,85 & 0,85 \\
\hline
\end{tabular}

viabilidade econômica do efeito da adição de um complexo multienzimático sobre o desempenho de frangos de corte alimentados com níveis crescentes de farelo de arroz de $12-42$ dias foi utilizado o índice bio-econômico, desenvolvido por GUIDONI et al. (1994). O Índice bio-econômico (IBE) foi calculado pela seguinte fórmula:

$\mathrm{IBE}=$ Ganho de peso - (preço médio do $\mathrm{kg}$ de ração/preço do kg do frango vivo)* consumo médio de ração por frango.

O preço do kg de frango vivo e os custos da ração foram calculados levando em consideração a variação mensal do frango e das matérias primas. $\mathrm{O}$ custo médio do kg de ração foi obtido pela média de consumo e o custo da ração na respectiva fase de criação. Os parâmetros avaliados foram submetidos à análise de variância e regressão pelo programa SAS, (1996). Para os parâmetros que apresentaram na análise de variância, valores de $\mathrm{F}$ significativo $(\mathrm{P}<0,05)$ foi aplicado o Teste de Tukey (5\%) para comparar as médias.

\section{RESULTADOS E DISCUSSÃO}

Os resultados das médias de peso corporal, consumo de ração, ganho de peso, conversão alimentar, índice bio econômico e Análise de variância são apresentados na tabela 3 , na qual não se verificou interação significativa entre níveis de FAI e suplementação enzimática em nenhum dos parâmetros avaliados.

Com a adição de níveis crescentes de farelo de arroz integral nas dietas, houve uma regressão linear significativa $(\mathrm{P}<0,05)$ com diminuição no peso corporal, consumo de ração e no ganho de peso das aves. Resultados semelhantes foram reportados por KRATZER \& PAYNE (1977), LÓPEZ et al. (1978), WARREN \& FARRELL (1991) e SOUZA \& LÓPEZ (1994). Alguns pesquisadores como BRENES (1992) e PENZ \& VIEIRA (1998) explicam que a redução no desempenho das aves se deve à presença de $\beta$ glucanos, pentosanas e polissacarídeos não amiláceos. Essas substâncias não são digeridas pelas

Tabela 2 - Composição Nutricional das dietas utilizadas durante a fase final (35-42 dias).

\begin{tabular}{|c|c|c|c|c|c|c|c|c|}
\hline Nutrientes & $0 \%$ (s/enz) & $0 \%$ (c/enz) & $10 \%$ (s/enz) & $10 \%$ (c/enz) & $20 \%$ (s/enz) & $20 \%$ (c/enz) & $30 \%$ (s/enz) & $30 \%$ (c/enz) \\
\hline $\mathrm{PB}(\%)$ & 18,00 & 18,00 & 18,00 & 18,00 & 18,00 & 18,00 & 18,00 & 18,00 \\
\hline $\mathrm{EM}(\mathrm{Kcal} / \mathrm{Kg})$ & 3,150 & 3,150 & 3,150 & 3,150 & 3,150 & 3,150 & 3,150 & 3,150 \\
\hline Cálcio (\%) & 0,88 & 0,78 & 0,88 & 0,78 & 0,88 & 0,78 & 0,88 & 0,78 \\
\hline P.disp. (\%) & 0,42 & 0,32 & 0,42 & 0,32 & 0,42 & 0,32 & 0,42 & 0,32 \\
\hline Sódio (\%) & 0,18 & 0,18 & 0,18 & 0,18 & 0,18 & 0,18 & 0,18 & 0,18 \\
\hline Arginina (\%) & 1,07 & 1,06 & 1,09 & 1,08 & 1,11 & 1,10 & 1,13 & 1,13 \\
\hline Lisina (\%) & 0,90 & 0,90 & 0,90 & 0,90 & 0,90 & 0,90 & 0,90 & 0,90 \\
\hline Met + Cys $(\%)$ & 0,60 & 0,60 & 0,60 & 0,60 & 0,60 & 0,60 & 0,60 & 0,60 \\
\hline Metionina (\%) & 0,60 & 0,60 & 0,60 & 0,60 & 0,60 & 0,60 & 0,60 & 0,60 \\
\hline Treonina (\%) & 0,35 & 0,35 & 0,35 & 0,35 & 0,35 & 0,35 & 0,35 & 0,35 \\
\hline Valina (\%) & 0,81 & 0,81 & 0,81 & 0,81 & 0,82 & 0,82 & 0,83 & 0,83 \\
\hline
\end{tabular}

Ciência Rural, v.34, n.2, mar-abr, 2004. 
Tabela 3 - Resultados das médias de Peso Corporal (PC), Consumo de Ração (CR), Conversão Alimentar (CA), Ganho Peso (GP), İndice Bio Econômico (IBE) e análise de variância na fase de $1-42$ dias de idade.

\begin{tabular}{lccccc}
\hline Tratamentos & PC $(\mathrm{kg})^{1}$ & $\mathrm{GP}(\mathrm{kg})^{2}$ & $\mathrm{CR}(\mathrm{kg})^{3}$ & $\mathrm{CA}$ & $\mathrm{IBE}$ \\
\hline \multicolumn{5}{c}{ Efeito dos níveis de farelo de arroz integral (FAI) } \\
$0 \%$ & $2,170 \mathrm{a}$ & $1,885 \mathrm{a}$ & $3,602 \mathrm{a}$ & 1,911 & 0,244 \\
$10 \%$ & $2,081 \mathrm{ab}$ & $1,784 \mathrm{ab}$ & $3,427 \mathrm{ab}$ & 1,933 & 0,201 \\
$20 \%$ & $2,048 \mathrm{ab}$ & $1,744 \mathrm{ab}$ & $3,337 \mathrm{ab}$ & 1,957 & 0,135 \\
$30 \%$ & $2,000 \mathrm{~b}$ & $1,700 \mathrm{~b}$ & $3,294 \mathrm{~b}$ & 1,982 & 0,124 \\
\multicolumn{5}{c}{ Efeito da enzima } \\
S/ enzima & 2,086 & 3,469 & 1,787 & 1,945 & 0,175 \\
C/ enzima & 2,063 & 3,441 & 1,770 & 1,946 & 0,181 \\
\multicolumn{5}{c}{ Valores de F } \\
FAI & $4,22 * *$ & $4,10 * *$ & $4,99 * *$ & 1,11 & - \\
Enzima & 0,44 & 0,33 & 0,24 & 0,01 & - \\
FAI X & 0,95 & 0,22 & 1,12 & 0,96 \\
Enzima & 4,123 & 3,55 & 4,873 & 3,69 & - \\
CV $(\%)$ & \multicolumn{5}{c}{-} \\
\hline
\end{tabular}

** $(\mathrm{P}<0,05) \quad$ Médias seguidas de letras iguais nas colunas não diferem entre si, pelo teste de Tukey.

${ }^{1}$ Efeito linear $\mathrm{Y}=2,156133-0,005428 \mathrm{X}$.

${ }^{2}$ Efeito linear $\mathrm{Y}=1,867633-0,005945 \mathrm{X}$.

${ }^{3}$ Efeito linear $Y=3,562900-0,007185 X$.

aves, porém se tornam solúveis, durante o processo de digestão, produzindo aumento da viscosidade intestinal da digesta. O aumento da viscosidade intestinal da digesta, por sua vez, diminui a velocidade de passagem dos alimentos ao longo do trato digestivo. Como conseqüência, à ave ingere menos ração, há dificuldade na ação das enzimas endógenas e interferência na difusão ou transporte dos nutrientes.

A conversão alimentar aumentou linearmente à medida que se aumentavam os níveis de FAI, mas não foi significativa. Isto pode ser atribuído a redução no ganho de peso e simultaneamente no consumo de ração (Tabela 3). KRATZER \& PAYNE (1977), FIALHO \& LÓPEZ (1991), testando níveis crescentes de FAI $(0,8,33,16,67$ e $25 \%)$, observaram efeito linear negativo para a conversão alimentar.

A suplementação enzimática não apresentou diferença estatística significativa em nenhum dos parâmetros avaliados. Resultados semelhantes foram verificados por BONATO et al. (2001). Por sua vez, SOTO-SALANOVA (1996) observou a manutenção do ganho de peso, com menor consumo e melhor conversão alimentar quando suplementou rações à base de milho e soja para frangos de corte com suplemento enzimático.

A redução dos níveis de $\mathrm{Ca}$ e $\mathrm{P}$ não prejudicou o desempenho das aves, demonstrando que a enzima foi eficiente em suplementar os níveis de $\mathrm{Ca}$ e $\mathrm{P}$ reduzidos. Pesquisadores como MUNARO et al. (1996), CONTE et al. (1999) chegaram a resultados semelhantes. Eles explicam que a fitase melhora a disponibilidade do fósforo de origem vegetal em dietas com baixo fósforo disponível, reduzindo a sua concentração nas excretas.

A análise bio-econômico demonstrou que à medida que se aumentavam os níveis de inclusão de FAI na dieta, o IBE reduzia linearmente, conforme a tabela 3.

\section{CONCLUSÃO}

Com aumento dos níveis de inclusão de FAI na dieta ocorre uma redução no peso corporal, ganho de peso e consumo de ração. A redução dos níveis de $\mathrm{Ca}$ e $\mathrm{P}$ nas dietas suplementadas com fitase não prejudica o desempenho das aves, e a inclusão de até $20 \%$ de FAI não prejudica o desempenho das aves, porém o IBE diminui com o aumento da inclusão, tornando inviável economicamente a adição do FAI na dieta.

\section{REFERÊNCIAS BIBLIOGRÁFICAS}

BEDFORD, M.R.; CLASSEN, E H.L. Reduction of intestinal viscosity through manipulation of dietary rye and pentosanase concentration is affected through changes in the carbohydrate composition of the intestinal aqueous phase and results in improved growth rate and feed conversion efficiency in broiler chicks. Jornal oF Nutrition, v.122, p.560-569, 1992.

BRENES, A. Influencia de la adición de enzimas sobre el valor nutritivo de las raciones en la alimentación aviar. Seleciones Avícolas, v.22, p.787-794, 1992.

BONATO, E. L. et al. Efeito da adição de enzimas em dietas com níveis crescentes de farelo de arroz integral sobre o desempenho de frangos de corte. In: CONFERÊNCIA APINCO, 2001, Campinas, SP. Revista Brasileira de Ciência Avícola, Suplemento 3, p.32, 2001.

CONTE, A.J. et al. Efeito da fitase na disponibilidade de fósforo e no desempenho de frangos de corte alimentados com dietas contendo farelo de arroz integral. In: REUNIÃO DA SBZ, 36., 1999, Porto Alegre, RS. Anais... Porto Alegre: SBZ,1999. 364p. p. 186.

DOMENE, S.M.A. Estudo do valor nutritivo mineral do farelo de arroz. Utilização do zinco, ferro, cobre e cálcio pelo rato em crescimento. 1996. 104f. Tese (Doutorado em Ciência da Nutrição) - UNICAMP.

FIALHO, F.B. Disponibilidade de manganês do farelo de arroz para frangos de corte. 1991. 156p. Dissertação (Mestrado em Nutrição Animal) - Universidade Federal do Rio Grande do Sul, 1991.

FIALHO, F.B.; LÓPEZ, J. Influência de níveis de farelo de arroz integral no desempenho de frangos de corte. In: 
REUNião ANUAL DA SBZ, 1991, João Pessoa, PB. Anais... João Pessoa : SBZ, 1991. p.338.

GUIDONI, A.L.; GODOI, C.R. de M.; BELLAVER, C. Uso do índice nutricional bio-econômico como medida do desempenho nutricional. In: REUNIÃO ANUAL DA SOCIEDADE BRASILEIRA DE ZOOTECNIA, 31., 1994, Maringá, PR. Anais... Maringá : SBZ, 1994. p.32.

JONGBLOED, A.W. et al. The role of microbial phytases in pig production. In: ENZYMES IN ANIMAL NUTRITION, 1993, Thurgau, Switzerland. Proceedings... Thurgau: Kartause Ittingen, 1993. p.173-180.

KELSAY, J.L. A review of research on effects of fiber intake on mam. American Jounal of Clinical Nutrition, v.31, n.1, p.142-159, 1978

KORIN, L.L. et al. Efect of ethanol extrat on nittrogencorrected true metabolizable energy for soybean meal with broilers and roosters. Poultry Science, Champaign, v.61, p.1576-1577, 1991

KRATZER, F. H.; PAYNE, C.G. Effect of autoclaving, hotwater treating, parboiling and addition os ethoxiquin on the value of rice bran as a dietary ingredient of chickens. Britney Poultry Science, Abingdon, v.18, p.475-82,1977.

LÓPEZ, J. et al. Farelo desengordurado de arroz na alimentação de pintos. Revista da Sociedade Brasileira de Zootecnia, Viçosa, v.7, n.1, p.43-52, 1978

MUNARO, F.A. et al. Efeito da fitase na biodisponibilidade do fósforo em rações com farelo de arroz desengordurado para frangos de corte. Revista da Sociedade Brasileira de Zootecnia, Viçosa, v.25, n.5, p.932-943, 1996.

PENZ, A.M. Enzimas em Rações para Aves e Suínos. Aditivos na produção de não-ruminantes. In: REUNIÃO ANUAL DA SBZ, 35., 1998. Botucatu, SP. Anais... Botucatu : SBZ, 1998. 375p. p. 165

PENZ, A.M.; VIEIRA, S.L. Nutrição na primeira semana. In: CONFERÊNCIA APINCO 98-SIMPÓSIO INTERNACIONAL SOBRE MANEJO DE PINTOS DE CORTE, 1998, Campinas, SP. Anais... Campinas : Facta 1998. p.121-139.

RAVINDRAN, V. et al. Effects of phytic acid on the performance of poultry and swine. In: COELHO, M.B.; KORNEGAY, E.T. PHYTASE IN ANIMAL NUTRITION AND WASTE MANAGEMENT, 1996, New Jersey. A BASF reference manual 1996... New Jersey : BASF, 1996. p.93110 .

ROSTAGNO, H.S. Exigências nutricionais e biodisponibilidade de fósforo para frangos de corte. In: SIMPÓSIO INTERNACIONAL SOBRE NUTRIÇÃO DE AVES, 1998, Campinas. Anais... Campinas : CBNA, 1998. p.1-27.

ROSTAGNO, H.S. Tabelas brasileiras para aves e suínos: composição de alimentos e exigências nutricionais de suínos e aves: tabelas brasileiras. 2.ed, Viçosa, 2000. $141 \mathrm{p}$.

ROTTER, B.A.; FROHLISH, A.A.; MARQUARDT, R.R Estimation of apparent protein digestibility using uric acidcorrected nitrogen values in poultry excreta. Poultry Sciense, Champaign, v.68, p.329, 1998.

SAS®. Statistical analisysis system. User's Guide: Stat, version 6.ed. Cary : SAS Institute, 1996. V.2.

SOTO-SALANOVA M. The use of enzymes to improve the nutricional value of corn-soy diets for poultry and swine. In: SIMPOSIO LATINO-AMERICANO DE NUTRIÇAO DE SUINOS E AVES, 1996, Campinas, SP. Proceedings... Campinas : Colégio Brasileiro de nutrição animal, 1996. p.113

SOUZA, G.A.; LÓPEZ, J. Farelo de arroz integral com fonte de fósforo em rações para frangos de corte. 1. desempenho e produtividade animal. Revista da Sociedade Brasileira de Zootecnia, Viçosa, v. 23, n.1, p.73- 84, 1994.

TEIXEIRA, A.S. Exigências nutricionais de zinco e sua biodisponibilidade em sulfatos e óxidos de zinco para pintos de corte. 1994. 172f. Tese (Doutorado em Produção Animal) - Universidade Federal do Rio Grande do Sul

TORIN, H.R. Utilização do farelo de arroz industrial. Composição e valor nutrificante em dietas recuperativa. 1991. 147f. Dissertação (Mestrado em Ciência da Nutrição) - UNICAMP.

VÖLKER, L.; TÜLLER, R. Effect of Roxazyme G supplementation to wheat - and wheat/barley-based diets on the performance of growing turkeys. In: ENZYMES IN ANIMAL NUTRITION SYMPOSIUM, 1993, Zurich. Proceedings... Zurich : Kartause Ittingen, 1993. p.141144

WARREN, B.E.; FARRELL, D.J. The nutritive value of full-fat and defatted Australian rice bran. V. The aparent retencion of minerals and apparent digestibility of amino acids in chickens and adult cockerels fitted with ileal cannulate. Animal Feed ScienceTechnology, v.34, p.323$42,1991$.

WENK, C. What are the benefits of carbohydrases in the nutrition of monogastric farm animals. In: ENZYMES IN ANIMAL NUTRITION, 1993, Thurgau, Switzerland. Proceedings... Thurgau : Kartause Ittingen, 1993. p.4148

WHITE, W.B. et al. Viscosity of beta-D-glucan as a factor in the enzymatic improvement of barley for chicks. Poultry Science, v.62, p.853-862, 1983.

ZANELLA, I. Suplementação enzimática em dietas avícolas. In: PRÉ-SIMPÓSIO DE NUTRIÇÃO ANIMAL: AVES E SUÍNOS, 2001, Santa Maria, RS. Anais... Santa Maria: Departamento de Zootecnia, UFSM, 2001. 69p. p 37. 